\title{
Perbandingan Preemptive Analgesia Kombinasi Ibuprofen 75 Miligram dan Parasetamol 250 Miligram per Oral dengan Parasetamol 1 Gram per Oral terhadap Lama Analgesik Pascabedah Odontektomi
}

\author{
Hilmy Manuapo, Reza W. Sudjud, Doddy Tavianto \\ Departemen Anestesiologi dan Terapi Intensif \\ Fakultas Kedokteran Universitas Padjadjaran/RSUP Dr. Hasan Sadikin Bandung
}

\begin{abstract}
Abstrak
Analgesik dosis tinggi dapat menimbulkan berbagai efek samping. Penggunaan kombinasi analgesik bekerja melalui mekanisme yang berbeda dan memiliki efek sinergis. Penelitian ini bertujuan mengetahui perbedaan lama analgesik antara kombinasi ibuprofen $75 \mathrm{mg}$ dan parasetamol $250 \mathrm{mg}$ per oral dibanding dengan parasetamol $1 \mathrm{~g}$ per oral terhadap nyeri pascabedah odontektomi. Penelitian eksperimental dengan uji klinis acak tersamar buta ganda terhadap 26 subjek penelitian yang menjalani odontektomi di RSUP Dr. Hasan Sadikin Bandung pada bulan Juli-Oktober 2019. Subjek dibagi menjadi kelompok P (Parasetamol) dan kelompok K (Kombinasi). Data hasil penelitian diuji secara statistik menggunakan Uji Mann-Whitney. Hasil penelitian ini didapatkan perbandingan lama analgesik pascabedah kelompok K $(74,23 \pm 15,79$ menit $)$ lebih lama dibanding dengan kelompok P $(50,76 \pm 17,22$ menit $)$ dengan $\mathrm{p}<0,05$. Hasil skor nyeri pascabedah odontektomi pada kelompok K $(2,92 \pm 0,75)$ lebih rendah dibanding dengan kelompok P $(3,92 \pm 0,86)$ dengan $\mathrm{p}<0,05$. Simpulan penelitian ini adalah kombinasi preemptive analgesia ibuprofen dan parasetamol per oral memiliki efek analgesik yang lebih lama dibanding dengan parasetamol per oral pada pascabedah odontektomi.
\end{abstract}

Kata kunci: Ibuprofen, kombinasi analgesik, manajemen nyeri, parasetamol, preemptive analgesia

\section{Comparison of Preemptive Analgesia using Oral Combination of Ibuprofen 75 Milligrams and Paracetamol 250 Milligram and Oral Paracetamol 1 Gram on Duration of Analgesics After Odontectomy}

\begin{abstract}
High dose analgesic can cause multiple side effects. Use of analgesics combination enable analgesics to work through different mechanisms and produce a synergistic effect. This study aimed to evaluate the analgesic effects of oral $75 \mathrm{mg}$ ibuprofen and $250 \mathrm{mg}$ paracetamol combination in comparison to oral $1 \mathrm{~g}$ paracetamol on post-odontectomy pain. This study was an experimental double blind randomized clinical trial conducted on 26 subjects who underwent odontectomy in Dr. Hasan Sadikin General Hospital Bandung during the period of July-October 2019. Subjects were divided into P (Paracetamol) group and K (combination) group. Data collected were statistically tested using the Mann-Whitney test. Results showed that the time when post-odontectomy pain started in K group ( $74.23 \pm 15.79$ minutes) was significantly longer when compared to that of $\mathrm{P}$ group ( $50.76 \pm 17.22$ minutes) with $\mathrm{p}<0.05$. The post-odontectomy pain score in $\mathrm{K}$ group $(2.92 \pm 0.75)$ was also lower than that of P group $(3.92 \pm 0.86)$, with $\mathrm{p}<0.05$. In conclusion, oral analgesic agent combinations have a longer analgesic effect than oral paracetamol only in post-odontectomy patients.
\end{abstract}

Key words: Combined analgesia, ibuprofen, pain management, paracetamol, preemptive analgesia 


\section{Pendahuluan}

Definisi nyeri menurut International Association for the Study of Pain (IASP) adalah suatu pengalaman sensorik dan emosional yang tidak menyenangkan yang berhubungan dengan kerusakan jaringan. Nyeri pascabedah merupakan pengalaman individual yang dipengaruhi oleh berbagai faktor, antara lain adat, budaya, jenis operasi, penyakit penyerta, rasa takut, kecemasan, dan depresi. Manajemen nyeri pascabedah merupakan hal penting karena nyeri yang tidak tertangani memiliki dampak negatif terhadap kehidupan sosial dan pekerjaan pasien. Prevalensi nyeri pascabedah dilaporkan sangat beragam sekitar $14 \%$ hingga $70 \%{ }^{1,2}$

Odontektomi merupakan prosedur yang paling sering dilakukan dalam rongga mulut. Jumlah kasus impaksi gigi geraham sekitar 33\% dari populasi. Berdasar data dari Hospital Episode Statistics, odontektomi di Inggris mencapai 63.000 tindakan per tahun dengan lebih dari sepertiga pasien pascabedah mengalami nyeri inflamasi yang hebat setelah tindakan. Derajat nyeri pascabedah odontektomi merupakan derajat ringan hingga sedang. Nyeri pascabedah odontektomi meningkat sebanding jumlah gigi yang dicabut hingga dapat mencapai derajat nyeri sedang dan berat. Obat parasetamol dan NSAID menghilangkan nyeri pascabedah derajat ringan hingga sedang. Penggunaan obat tersebut pada saat ini telah digunakan secara luas pada manajemen nyeri pascabedah odontektomi. ${ }^{1-4}$

Penggunaan parasetamol atau ibuprofen dosis tunggal memiliki efek analgesik yang cukup baik, tetapi beberapa penelitian menyatakan timbulnya efek samping terutama berupa mual, muntah, kerusakan mukosa lambung, dan alergi. Berbagai penelitian sebelumnya menyatakan kombinasi analgesik memiliki mekanisme kerja berbeda dan efek sinergis sehingga menimbulkan efek analgesik yang lebih kuat dengan efek samping lebih sedikit. 5

Teknik preemptive analgesia merupakan salah satu cara untuk mencegah sensitisasi nosiseptor perifer akibat pelepasan neurotransmiter dan mediator inflamasi. Beberapa penelitian menyatakan tidak ada perbedaan derajat nyeri antara pemberian analgesik sebelum dan sesudah insisi. Penelitian lain menyatakan teknik ini memiliki keuntungan yang signifikan secara statistik. ${ }^{7-9}$

Tujuan penelitian ini adalah mengkaji perbandingan efek preemptive analgesia antara kombinasi ibuprofen $75 \mathrm{mg}$ dan parasetamol $250 \mathrm{mg}$ per oral dibanding dengan parasetamol $1 \mathrm{~g}$ per oral terhadap lama analgesik pascabedah odontektomi. ${ }^{10,11}$

\section{Subjek dan Metode}

Penelitian ini merupakan penelitian eksperimental dengan desain uji klinis acak tersamar buta ganda yang dilakukan terhadap 26 subjek penelitian. Penelitian dilakukan di Ruang Pemulihan RSUP Dr. Hasan Sadikin jalan Pasteur no. 38 Bandung sejak bulan JuliOktober 2019. Subjek penelitian ini adalah pasien yang menjalani operasi odontektomi. Kriteria inklusi penelitian ini, yaitu operasi odontektomi 2-4 gigi, status fisik American Society of Anesthesiologists (ASA) kelas I, usia 18-40 tahun, tingkat pendidikan minimal sekolah lanjutan tingkat pertama. Kriteria eksklusi, yaitu body mass index (BMI) $>30$, memiliki riwayat penyakit ulkus peptikum, penyakit kelainan darah yang berat, kelainan fungsi ginjal dan hati, mengonsumsi NSAID dalam 24 jam sebelum operasi, riwayat penyakit kejiwaan dan penyalahgunaan obatobatan, hamil atau menyusui, serta riwayat alergi obat-obatan yang digunakan dalam penelitian ini. Kriteria pengeluaran, yaitu operasi lebih dari 4 jam atau pasien mengalami reaksi alergi selama pembedahan.

Besar sampel ditentukan berdasar atas perhitungan statistik untuk perbandingan dua rerata tidak berpasangan dengan menetapkan taraf kepercayaan 95\% dan kuasa uji (power test) $80 \%$ dan didapatkan jumlah sampel minimal untuk tiap-tiap kelompok 13 orang sehingga total sampel untuk 2 kelompok adalah 26 orang. Pengambilan sampel dilakukan secara consecutive sampling dan 
alokasi subjek ke dalam salah satu kelompok dilakukan secara random blok permutasi.

Setelah mendapat persetujuan Komite Etik Penelitian Kesehatan Fakultas Kedokteran Universitas Padjadjaran/Rumah Sakit Umum Pusat Dr. Hasan Sadikin Bandung No. LB.02.01/X.6.5/212/2019, subjek penelitian menandatangani persetujuan (informed consent) tentang penelitian yang dilakukan.

Seluruh pasien diberikan obat analgesik dalam bentuk kapsul yang sama 2 jam sebelum operasi. Grup K (Kombinasi) diberikan kapsul berisi ibuprofen $75 \mathrm{mg}$ + parasetamol $250 \mathrm{mg}$ dan Grup P (Parasetamol) diberikan kapsul berisi parasetamol 1 gram 2 jam sebelum operasi. Semua pasien dibawa ke kamar operasi dan dilakukan pemasangan alatalat pemantauan seperti tekanan darah non invasif, saturasi, elektrokardiografi, laju nadi, dan laju napas.

Induksi dilakukan dengan fentanil $2 \mathrm{mcg} /$ $\mathrm{kgBB}$, propofol $2 \mathrm{mg} / \mathrm{kgBB}$, dan atrakurium $0,5 \mathrm{mg} / \mathrm{kgBB}$. Pemeliharaan anestesi dengan sevofluran $1-2$ vol\% dan $\mathrm{N}_{2} \mathrm{O}: \mathrm{O}_{2}=50 \%: 50 \%$. Pada akhir operasi diberikan neostigmin $0,05 \mathrm{mg} / \mathrm{kgBB}$ dan sulfas atrofin $0,02 \mathrm{mg} /$ kgBB. Subjek penelitian diekstubasi setelah memberikan respons terhadap perintah verbal, saturasi lebih dari 95\%, volum tidal lebih dari $6 \mathrm{~mL} / \mathrm{kgBB}$, laju napas $10-14 \mathrm{x} /$ menit dan dipindahkan ke ruang pemulihan.

Lama operasi diukur dengan stopwatch oleh peneliti dengan satuan waktu menit, hasil lama operasi dicatat dengan pembulatan waktu setiap 5 menit. Observasi nyeri pascabedah dengan menggunakan NRS dilakukan selama

Tabel 1 Karakteristik Umum Subjek Penelitian

\begin{tabular}{|c|c|c|c|}
\hline \multirow[b]{2}{*}{ Variabel } & \multicolumn{2}{|c|}{ Kelompok } & \multirow[b]{2}{*}{ Nilai $p$} \\
\hline & $\begin{array}{c}P \\
n=13\end{array}$ & $\begin{array}{c}K \\
n=13\end{array}$ & \\
\hline Usia (tahun) & & & 0,72 \\
\hline Rerata \pm Std & $24,76 \pm 6,69$ & $25,30 \pm 6,65$ & \\
\hline Median & 21,00 & 25,00 & \\
\hline Rentang & $18,00-36,00$ & $18,00-36,00$ & \\
\hline Jenis kelamin & & & 1,00 \\
\hline Laki-laki & 5 & 5 & \\
\hline Perempuan & 8 & 8 & \\
\hline BMI $\left(\mathrm{kg} / \mathrm{m}^{2}\right)$ & & & 0,20 \\
\hline Rerata \pm Std & $23,28 \pm 1,86$ & $22,18 \pm 2,18$ & \\
\hline Median & 23,20 & 21,50 & \\
\hline Rentang & $18,30-25,60$ & $19,40-25,30$ & \\
\hline Pendidikan & & & 1,00 \\
\hline SMP & 1 & 1 & \\
\hline SMA & 8 & 8 & \\
\hline D3 & 0 & 1 & \\
\hline $\mathrm{S} 1$ & 4 & 3 & \\
\hline Lama pembedahan (jam) & & & 0,76 \\
\hline Rerata \pm Std & $1,29 \pm 0,41$ & $1,25 \pm 0,35$ & \\
\hline Median & 1,25 & 1,16 & \\
\hline Rentang & $0,67-2,00$ & $0,75-2,00$ & \\
\hline NRS preoperatif & & & 0,51 \\
\hline Rerata \pm Std & $1,38 \pm 0,50$ & $1,53 \pm 0,51$ & \\
\hline Median & 1,00 & 2,00 & \\
\hline Rentang & $1,00-2,00$ & $1,00-2,00$ & \\
\hline
\end{tabular}

Keterangan: untuk data numerik nilai p diuji dengan uji T tidak berpasangan, apabila data berdsitribusi normal dengan alternatif Uji Mann-Whitney, apabila data tidak berdistribusi normal. Nilai kemaknaan berdasar nilai $\mathrm{p}<0,05$. Tanda* menunjukkan nilai $\mathrm{p}<0,05$ artinya signifkan atau bermakna secara statistik 
Tabel 2 Lama Analgesik Pascabedah

\begin{tabular}{lccc}
\hline \multirow{2}{*}{ Lama Analgesik Pascabedah } & \multicolumn{2}{c}{ Kelompok } & Nilai p \\
\cline { 2 - 3 } & $\mathbf{P}$ & $\mathbf{n}$ & Nenit) \\
\cline { 2 - 4 } & $\mathbf{n = 1 3}$ & $74,23 \pm 15,79$ & $0.001^{*}$ \\
Rerata \pm Std & $50,76 \pm 17,22$ & 75,00 & \\
Redian & 50,00 & $45,00-100,00$ & \\
\hline
\end{tabular}

Keterangan: untuk data numerik nilai p diuji dengan uji T tidak berpasangan apabila data berdistribusi normal dengan alternatif uji Mann-Whitney apabila data tidak berdistribusi normal. Nilai kemaknaan berdasar nilai $\mathrm{p}<0,05$. Tanda* menunjukkan nilai $\mathrm{p}<0,05$ artinya signifkan atau bermakna secara statistik

subjek di ruang pemulihan selama 2 jam dengan interval 30 menit.

Metode NRS dilakukan dengan cara pasien diminta untuk memilih angka 0 hingga 10 (bilangan bulat). Angka 0 dinyatakan sebagai tidak ada intensitas rasa nyeri sama sekali dan angka 10 menggambarkan nyeri yang sangat hebat. Tim peneliti mencatat waktu lama analgesik menggunakan stopwatch dalam satuan menit sejak pasien selesai tindakan anestesi (t0) hingga pasien mengeluhkan nyeri pascabedah pertama kali dengan NRS $\geq 3$. Pasien diberikan obat analgesik pertolongan pascabedah dengan petidin $0,5 \mathrm{mg} / \mathrm{kgBB}$ bolus intravena jika penilaian NRS $\geq 3$.

Analisis statistik data hasil penelitian menggunakan Uji Mann-Whitney dan uji chisquare dengan alternatif Uji KolmogorovSmirnov dan Eksak Fisher. Data hasil penelitian dicatat dan diolah menggunakan program statistical product and service solution (SPSS) versi 24.0 for windows.

\section{Hasil}

Gambaran karakteristik subjek penelitian antara kelompok $\mathrm{P}$ dan $\mathrm{K}$ berdasar usia, jenis kelamin, BMI, pendidikan, lama operasi, dan

Tabel 3 Perbandingan Skor Nyeri Pascabedah (NRS)

\begin{tabular}{|c|c|c|c|}
\hline \multirow[b]{2}{*}{ Variabel } & \multicolumn{2}{|c|}{ Kelompok } & \multirow[b]{2}{*}{ Nilai p } \\
\hline & $\begin{array}{c}P \\
n=13\end{array}$ & $\begin{array}{c}K \\
n=13\end{array}$ & \\
\hline \multicolumn{4}{|l|}{$\mathrm{T} 1$} \\
\hline $\begin{array}{l}\text { Rerata } \pm \text { Std } \\
\text { Median } \\
\text { Rentang } \\
\text { T2 }\end{array}$ & $\begin{array}{c}2,46 \pm 0,51 \\
2,00 \\
2,00-3,00\end{array}$ & $\begin{array}{c}1,61 \pm 0,50 \\
2,00 \\
1,00-2,00\end{array}$ & $0,003^{*}$ \\
\hline $\begin{array}{l}\text { Rerata } \pm \text { Std } \\
\text { Median } \\
\text { Rentang }\end{array}$ & $\begin{array}{c}2,92 \pm 0,64 \\
3,00 \\
2,00-4,00\end{array}$ & $\begin{array}{c}2,15 \pm 0,55 \\
2,00 \\
1,00-3,00\end{array}$ & $0,009 *$ \\
\hline $\begin{array}{l}\text { T3 } \\
\text { Rerata } \pm \text { Std } \\
\text { Median } \\
\text { Rentang }\end{array}$ & $\begin{array}{c}3,30 \pm 0,63 \\
3,00 \\
2,00-4,00\end{array}$ & $\begin{array}{c}2,46 \pm 0,66 \\
3,00 \\
1,00-3,00\end{array}$ & $0,009 *$ \\
\hline $\mathrm{T} 4$ & & & $0.007^{*}$ \\
\hline Rerata \pm Std & $3,92 \pm 0,86$ & $2,92 \pm 0,76$ & \\
\hline Median & 4,00 & 3,00 & \\
\hline Rentang & $2,00-5,00$ & $2,00-4,00$ & \\
\hline
\end{tabular}

Keterangan: untuk data numerik nilai p diuji dengan uji Mann-Whitney karena data tidak berdistribusi normal. Nilai kemaknaan berdasar nilai $\mathrm{p}<0,05$. Tanda* menunjukkan nilai $\mathrm{p}<0,05$ artinya signifkan atau bermakna secara statistik 
Tabel 4 Perbandingan Efek Samping Pemberian Obat

\begin{tabular}{lccc} 
& \multicolumn{2}{c}{ Kelompok } & \\
\cline { 2 - 4 } \multicolumn{1}{c}{ Efek Samping } & $\mathbf{P}$ & $\mathbf{K}$ & Nilai p \\
& $\mathbf{n = 1 3}$ & $\mathbf{n = 1 3}$ & \\
\hline Mual & 1 & 0 & 1.00 \\
Nyeri ulu hati & 1 & 12 & \\
Tidak ada & 11 & 12 & \\
\hline
\end{tabular}

Keterangan: untuk data kategorik nilai p dihitung berdasar uji chi-square dengan alternatif Uji Kolmogorov Smirnov dan Eksak Fisher apabila syarat chi-square tidak terpenuhi. Nilai kemaknaan berdasar nilai $\mathrm{p}<0,05$. Tanda* menunjukkan nilai $\mathrm{p}<0,05$ artinya signifkan atau bermakna secara statistik

NRS preoperatif tidak terdapat perbedaan bermakna ( $p>0,05$; Tabel 1$)$.

Penilaian lama analgesik pascabedah menunjukkan kelompok $\mathrm{K}$ memiliki efek analgesik pascabedah yang lebih lama $(74,23$ menit) dibanding dengan kelompok $\mathrm{P}(50,76$ menit) dengan perbedaan yang bermakna ( $\mathrm{p}<0,05$; Tabel 2).

Penilaian skor nyeri pascabedah dengan menggunakan NRS menunjukkan kelompok K pada waktu T1, T2, T3, T4 memiliki skor nyeri pascabedah yang lebih rendah dibanding dengan kelompok $P$ dengan perbedaan yang bermakna $(p<0,05$; Tabel 3$)$.

Penilaian efek samping pemberian obat menunjukkan kelompok $\mathrm{K}$ memiliki efek samping mual sebanyak 1 dari 13 subjek dan kelompok P terjadi mual dan nyeri ulu hati masing- masing sebanyak 1 dari 13 subjek dengan perbedaan yang tidak bermakna ( $p>0,05$; Tabel 4).

\section{Pembahasan}

Nyeri merupakan suatu perasaan yang bersifat subjektif yang dipengaruhi oleh beberapa faktor antara lain usia, jenis kelamin, dan tingkat pendidikan. Pencegahan nyeri dengan preemptive analgesia dan multimodal menunjukkan angka yang cukup memuaskan pada pascabedah odontektomi. Karakteristik subjek dua kelompok pada penelitian ini tidak ada perbedaan bermakna $(p>0,05)$ sehingga sampel penelitian pada kedua kelompok dianggap homogen dan layak untuk dibandingkan. ${ }^{2,12}$

Lama analgesik pascabedah pada kelompok
$P(50,76$ menit $)$ lebih singkat dibanding dengan kelompok K (74,23 menit) dengan perbedaan bermakna $(p<0,05)$. Hal ini disebabkan oleh ibuprofen memiliki perbedaan absorbsi dan metabolisme dengan parasetamol. Ibuprofen lebih mudah mencapai onset, durasi aksi dan metabolisme sedikit lebih lama dibanding dengan parasetamol.

Hasil penelitian ini sesuai dengan penelitian sebelumnya yang membandingkan farmakokinetik antara ibuprofen, parasetamol, dan ketoprofen pada penanganan nyeri pascabedah odontektomi. ${ }^{13}$

Skor nyeri pascabedah odontektomi kelompok Kpada waktu T1, T2, T3, dan T4 lebih rendah dibanding dengan kelompok $\mathrm{P}$ dengan perbedaan yang signifikan atau bermakna $(p<0,05)$. Hal ini disebabkan oleh pendekatan multimodal dengan menggunakan beberapa agen dapat mengurangi aktivitas reseptor nyeri dan respons hormon lokal terhadap kerusakan. Kombinasi analgesik merupakan salah satu teknik penanganan nyeri dengan berbagai target jaras nyeri, baik di perifer dan atau sistem saraf pusat.

Kombinasi ini memiliki efek sinergis dan lebih efektif dibanding dengan dosis tunggal. Jaras nyeri terdiri atas 4 tahap, yaitu tranduksi, transmisi, modulasi, dan persepsi. Parasetamol terutama mempunyai aktivitas pada tahap persepsi dengan menghambat prostaglandin dan enzim cyclooxygenase sentral dan perifer. Ibuprofen terutama bekerja di tahap tranduksi dengan menghambat sintesis prostaglandin oleh cyclooxygenase dan mediator inflamasi lainnya. Efek ini menyebabkan hambatan proses terjadinya nyeri pada kombinasi 
lebih kuat dibanding dengan penggunaan tunggal. ${ }^{14-16}$

Hasil penelitian ini sesuai dengan yang dilakukan di Selandia Baru terhadap 159 pasien yang dibagi menjadi empat kelompok. Tiap-tiap kelompok mendapat perlakuan berupa kombinasi analgesik parasetamol dan ibuprofen dengan berbagai dosis yang dibandingkan dengan plasebo. Hasil penelitian ini menyatakan bahwa semua dosis kombinasi analgesik memiliki efek analgesik yang lebih superior dibanding dengan analgesik tunggal. ${ }^{16}$

Hasil penelitian ini juga sesuai dengan hasil penelitian terhadap 71 pasien pascabedah nekrosis pulpa yang menyatakan penggunaan kombinasi analgesik parasetamol dan ibuprofen dapat menurunkan skor nyeri dibanding dengan dosis tunggal. ${ }^{16}$

Perlakuan berupa preemptive analgesia pada penelitian ini didasarkan pada pencegahan proses amplikasi sinyal nyeri sebelum terjadinya tindakan pembedahan. Hal ini bertujuan mengurangi atau mencegah munculnya sensitisasi dan amplifikasi nyeri di perifer dan pusat yang bekerja pada saat sebelum insisi hingga awal masa pascabedah., ${ }^{7,8}$

Efek samping dari pemberian obat analgetik baik dosis tunggal atau kombinasi masih merupakan masalah yang sering muncul. Inhibisi COX-1 oleh NSAID akan memberikan efek samping, salah satunya efek terhadap saluran gastrointestinal. Gejala yang sering muncul berupa mual, muntah, nyeri ulu hati dan perdarahan di saluran cerna.

Pada penelitian ini efek samping yang muncul berupa mual dan nyeri ulu hati, pada 2 pasien kelompok $\mathrm{P}$ dan 1 pasien kelompok K. Keterbatasan penelitian ini jumlah sampel terlalu sedikit untuk menyimpulkan efek samping sehingga butuh penelitian lanjutan dengan sampel yang lebih besar. ${ }^{4}$

\section{Simpulan}

Obat kombinasi preemptive analgesia ibuprofen dan parasetamol per oral memiliki efek analgesik yang lebih lama dibanding dengan parasetamol dosis tunggal.

\section{Daftar Pustaka}

1. koft A, Patel NB. Physiology of pain. Guide to pain management in low-resource settings. Intern Assoc Study Pain. 2010;13:14

2. Tocher J, Rodgers S, Smith MA, Watt D, Dickson L. Pain management and satisfaction in postsurgical patients. J Clin Nurs. 2012;21(23-24):3361-71.

3. Buenaventura RM, Adlaka RM, Sehgal NM. Opioid complications and side effects. Pain Physician. 2008;11:105-20.

4. Bailey E, Worthington HV, van Wijk A, Yates JM, Coulthard P, Afzal Z. Ibuprofen and/or paracetamol (acetaminophen) for pain relief after surgical removal of lower wisdom teeth. Cochrane Database Systematic Rev. 2013;12(CD004624).

5. Hyllested M, Jones S, Pedersen J, Kehlet H. Comparative effect of paracetamol, NSAIDs or their combination in postoperative pain management: a qualitative review. $\mathrm{Br} \mathrm{J}$ Anaesth. 2002;88(2):199-214.

6. Au AHY, Choi SW, Cheung CW, Leung YY. The efficacy and clinical safety of various analgesic combinations for postoperative pain after third molar surgery: a systematic review and meta-analysis. PLoS One. 2015;10(6):e0127611.

7. Kissin I. Preemptive analgesia. Anesthesiology. 2000;93(4):1138-43.

8. Kelly DJ, Ahmad M, Brull SJ. Preemptive analgesia I: physiological pathways and pharmacological modalities. Can J Anaesth. 2001;48(10):1000-10.

9. Møiniche S, Kehlet H, Dahl JB. A Qualitative and quantitative systematic review of preemptive analgesia for postoperative pain relief the role of timing of analgesia. Anesthesiology: J Am Soc Anesth. 2002;96(3):725-41.

10. Ahmed SS, ElSharrawy EA, Hamed TA. Clinical evaluation of cox-2 inhibitor for management of post operative complications after odontectomy of impacted lower third molar. J Am Sci. 2014;10(11):60-3.

11. Aravena PC, Cartes-Velásquez R, Rosas C. Signs and symptoms of postoperative 
complications in third molar surgery. J Int Dent Med Res. 2015;8(3):140.

12. Wells LK, Drum M, Nusstein J, Reader A, Beck M. Efficacy of ibuprofen and ibuprofen/ acetaminophen on postoperative pain in symptomatic patients with a pulpal diagnosis of necrosis. J Endod. 2011; 37(12):1608-12.

13. Olson NZ, Otero AM, Marrero I, Tirado S, Cooper S, Doyle G, dkk. Onset of analgesia for liquigel ibuprofen $400 \mathrm{mg}$, acetaminophen $1.000 \mathrm{mg}$, ketoprofen $25 \mathrm{mg}$, and placebo in the treatment of postoperative dental pain. J Clin Pharmacol. 2001;41:1238-47.
14. Anderson BJ. Paracetamol (acetaminophen): mechanisms of action. Ped Anesth. 2008;18(10):915-21.

15. Merry A, Gibbs R, Edwards J, Ting G, Frampton C, Davies E, dkk. Combined acetaminophen and ibuprofen for pain relief after oral surgery in adults: a randomized controlled trial. $\mathrm{Br} \mathrm{J}$ Anaesth. 2010;104(1):80-8.

16. Atkinson HC, Currie J, Moodie J, Carson S, Evans S, Worthington JP, dkk. Combination paracetamol and ibuprofen for pain relief after oral surgery: a dose ranging study. Eur J Clin Pharmacol. 2015;71(5):579-87. 